\title{
Prevalence and correlates of depression among Nigerian stroke survivors
}

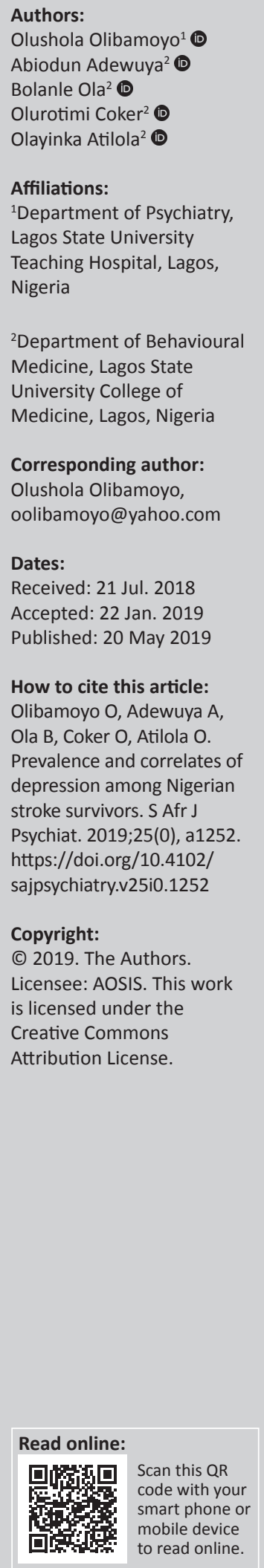

Background: There is mixed evidence for the hypothesis that the risk of depression after stroke is influenced by the location of lesions in the hemispheres, demographic and clinical factors, and disability of stroke survivors.

Aim: The current study determined the prevalence of depression and its socio-demographic and clinico-pathological correlates among stroke survivors in a tertiary hospital in Lagos, Nigeria.

Method: The cross-sectional study was carried out among 112 adult patients with a clinical history of stroke confirmed by neuroimaging. Depression was diagnosed using Mini International Neuropsychiatric Interview. The socio-demographic profile was obtained, and cognitive impairment was assessed using the Mini-Mental State Examination. Stroke severity was assessed retrospectively using the National Institute of Health Stroke Scale and current disability was measured using the Modified Rankin Scale.

Results: There were 48 (42.9\%) stroke survivors with a clinical diagnosis of depression. Using binary logistic regression, the independent determinants of depression were younger age, unemployment, perceived poor social support, increasing number of previous admissions because of stroke, cognitive impairment, severity of stroke and current disability status. However, there was no significant association between depression and lesion location.

Conclusion: Depression is a common associate of stroke, and there is a need for sustained focus on young stroke survivors with severe stroke, especially those who do not have social support and have low socio-economic status, who may have a higher risk of developing depression following stroke.

Keywords: Post-Stroke depression; Lesion location; Stroke severity; Disability; Sociodemographic; Clinical factors.

\section{Introduction}

Stroke is a recognised medical emergency, ${ }^{1}$ and it has remained a major health problem worldwide because of its high prevalence and because it is a leading cause of adult physical disability. ${ }^{2}$ Globally, about 10.3 million new cases of stroke yearly and 25.7 million stroke survivors were estimated in 2013, ${ }^{3}$ and it was among the top 10 leading causes of years of life lost worldwide in 2016. ${ }^{4}$ Stroke is defined as rapidly developing clinical signs of focal or global disturbance of cerebral functions, with symptoms lasting $24 \mathrm{~h}$ or longer or leading to death with no apparent cause other than that of vascular origin. ${ }^{5}$

The World Health Organization estimates suggest that $8 \%$ of all first-ever strokes occur in Africa and that $5 \%$ of stroke survivors worldwide live in Africa ${ }^{5}$; further, the burden of stroke in low- and middle-income countries accounts for over $87 \%$ of disability adjusted life years. ${ }^{6}$ This is a result of overwhelming costs incurred by the health systems and complications being under-recognised and undertreated. ${ }^{7}$

A stroke survivor is an individual who has been diagnosed as having a stroke, regardless of the level of handicap. ${ }^{8}$ Among survivors, neuropsychiatric disturbances are frequently seen in clinical practice, and the commonest is depression. ${ }^{8}$ Prevalence of post-stroke depression (PSD) from studies worldwide varies from $9 \%$ to $53 \%, 9,10,11$ while Nigerian studies of PSD also have rates varying from $16.2 \%$ to $52.9 \%{ }^{12,13,14,15,16,17,18,19,20,21,22}$ Post-stroke depression has profound effects on the lives of both survivors and caregivers. ${ }^{23}$

Two theories of PSD have been largely adopted. The first suggests that PSD is a result of specific brain lesion and presumably subsequent changes in neurotransmitters, while the second describes it as a psychological reaction to the clinical consequence of stroke. Previous studies on PSD and 
lesion location showed that the association is influenced by patient's selection, study design and time difference of measurement of depression. ${ }^{10}$

Moreover, earlier reviews mostly found stroke-related factors (lesion location, cognitive impairment and severity of stroke) to be responsible for depression to a large extent; however, in addition to these, different patient-related factors are found equally responsible in causing PSD, for example, age, gender, educational level and social support. ${ }^{24}$

Severity of impairment in activities of daily living and functional status has been frequently associated with PSD. Most studies on PSD found a statistically significant relation between the severity and existence of PSD and severity of impairment of activities of daily living. ${ }^{25,26}$

This study will provide information about PSD in Nigeria and simultaneously evaluate the relationship between PSD and the socio-demographic and clinico-pathological correlates of depression among survivors. Such an approach aids better understanding of PSD, given that depression in the general population is multi-causal.

\section{Method and materials Setting}

This was a cross-sectional study that was carried out at the neurology outpatient department of the Lagos State University Teaching Hospital, Ikeja. The clinic receives an average of 150 stroke-related follow-up patients in a year.

\section{Participants}

The respondents were adult stroke survivors (aged 18-65 years). The inclusion criteria were a previous history of stroke not less than 6 months prior and confirmation by neuroimaging (computed tomography scan-magnetic resonance imaging) of the brain within the acute episode of stroke (within 7 days of stroke).

Exclusion criteria were history of any psychotic disorder, history of pre-stroke mood disorder, language impairment severe enough to prevent neuro-psychiatry assessment, history of other central nervous disorders (head injury, multiple sclerosis, etc.) and acute illness preventing proper assessment.

A calculated sample size of 112, from a finite population of 150 regular follow-up patients, was needed for a $95 \%$ confidence interval in detecting a margin of error of 0.05 using a prevalence of $30.0 \%$ from a similar study ${ }^{15}$ as prior judgement of the correct value and $10 \%$ attrition rate.

\section{Instruments}

A pro forma questionnaire was used to collect sociodemographic data, which included a question on the level of social support received from family and friends, while clinical variables about stroke location (neuroimaging report), stroke type, stroke severity and number of stroke episodes were obtained from participants' case files:

1. Depression was assessed using the depression module of the Mini International Neuropsychiatric Interview (MINI) English Version 5.0.0. The MINI has an acceptably high validation and reliability score and can be administered in a much shorter period of time when compared to the Structured Clinical Interview for DSMIII, Patient edition and Composite International Diagnostic Interview. It has been used in various studies in Nigeria. ${ }^{27}$

2. Mini-Mental State Examination (MMSE): The MMSE is an interviewer-rated instrument used in assessing cognitive function. The maximum score is 30, with normal individuals scoring 24 and above, while a score of less than 24 indicative abnormal cognitive function. It has been used in Nigerian studies..$^{28}$

3. National Institute of Health Stroke Scale (NIHSS): The NIHSS is an objective clinical tool used in the evaluation of stroke severity. It comprises 15 items of neurologic examination. It is scored from 0 to a maximum of 42 . A high NIHSS score signifies severe stroke, and it has been shown to be the best predictor of outcome. It has been validated in Nigeria; a score equal to or greater than 16 forecasts a high probability of severe disability and a score of less than 16 forecasts good recovery. ${ }^{29}$ The admission stroke severity was obtained from the case files retrospectively using NIHSS.

4. Modified Rankin Scale (MRS): The MRS measures independence rather than performance of specific tasks. The scale consists of six grades from 0 to 5 . Patients with a score of $0-3$ were categorised as having a good outcome (not handicapped) and those with a score of 4-5 as handicapped. ${ }^{30}$ It has been used in Nigerian studies of stroke survivors. ${ }^{17}$

\section{Procedure}

Participants were recruited using simple random sampling without replacement, where seven participants were picked from an average of 10 stroke survivors each clinic day via balloting. Recruitment was carried out over 8 weeks. None of the recruited participants declined consent.

Literate patients were allowed to complete the pro forma questionnaire on their own, while those who were not had their answers recorded accordingly. The MINI, MRS, NIHSS and MMSE were administered by researchers who were trained on the use of the MINI prior to data collection, during which interrater reliability was measured. The diagnosis of stroke was made by a consultant neurologist, while neuroimaging was reported by a consultant radiologist. The participants who had depression were informed about it, and their managing physicians were also informed about the need to treat.

\section{Data analysis}

The data were coded, entered into a statistical package and cleaned. The statistical analysis was performed using SPSS 
version 23. Categorical variables were summarised with frequencies and percentages, while continuous variables were summarised with their mean, median, range and standard deviation.

The sampled population was divided into diagnostic groups of depressed and non-depressed individuals. The chi-square test was used to find the significance of study parameters on categorical variables, while the Mann-Whitney $U$ test was used to analyse continuous variables (they were not normally distributed) between the two groups. The $p$-value was set at 0.05 . Independent predictors of depression were determined by binary logistic regression. A $p$-value of less than 0.05 was considered significant.

\section{Ethical consideration}

Approval (LREC/06/10/732) was obtained from the Ethics and Research Committee of Lagos State University Teaching Hospital (NHREC04/04/2008) before commencement of the study. Written informed consent was obtained from all participants after the aims, objectives and purpose of the study were explained to them. Confidentiality and voluntariness regarding participation were also explained.

\section{Results}

A total of 112 patients were recruited, assessed and analysed. The same number was analysed. The mean age was $56.71 \pm$ 6.49 years, and there were 67 (59.8\%) males. Eighty (71.4\%) were married, $71(63.4 \%)$ were from the Yoruba ethnic group and $78(69.6 \%)$ were Christians.

Up to $47(42.0 \%)$ had tertiary education, while 67 (59.8\%) were self-employed. The majority $(66 ; 58.9 \%)$ collected a monthly salary or allowance between $\$ 70$ and $\$ 130$, while $85(75.9 \%)$ were living with their nuclear family. Moreover, $90(80.4 \%)$ rated their perceived social support from family members as fair.

Neuroimaging of both MRI and CT scans showed that $62(55.4 \%)$ had right hemisphere stroke, while 88 (78.6\%) experienced infarction. The mean duration of stroke was $51.78 \pm 46.21$ months. The majority of respondents (94; $83.9 \%$ ) had had only one episode of stroke, whereas five (4.5\%) had had three episodes. Only seven (6.3\%) respondents had had three or more hospitalisations resulting from stroke. The mean MMSE score was $27.42 \pm 2.42$, and eight (7.1\%) respondents had mild cognitive impairment.

The mean NIHSS score was $15.46 \pm 3.00$, and 47 (42.0\%) participants scored 16 and above, which forecasted severe stroke. The mean MRS score was $1.69 \pm 1.19$, and 12 respondents $(10.7 \%)$ showed no symptoms.

The rate of major depressive disorder using the MINI was found to be $42.9 \%$ in the studied population.

\section{Correlates of depression among stroke survivors}

Post-stroke depression was significantly $(U=967.50$, $p=0.001$ ) associated with younger age, as indicated in the Mann-Whitney U test; hence, depression in stroke survivors decreases with increasing age.

There is a significant risk $(p<0.001)$ of PSD in survivors who are unemployed $(78.6 \%)$ compared to those employed by others (35.5\%); however, being self-employed carried the least risk of having depression (29.9\%). Further, Mann-Whitney $U$ test indicated that PSD was significantly $(U=1051.50$, $p=0.004$ ) associated with lower monthly allowance.

Survivors with good social support had $16.7 \%$ risk of depression compared with $90.0 \%$ by survivors with poor social support, which was statistically significant $(p=0.001)$. Moreover, $34.7 \%$ of stroke survivors with one previous admission had PSD; this rate increased to $80.0 \%$ in survivors with two previous admissions and practically 100\% in survivors with three or more previous admissions. For cognitive function, $38.5 \%$ of those without cognitive impairment had PSD, while $100 \%$ of those with mild cognitive impairment had PSD.

There were 13 patients scoring $4-5$ on the MRS, and 12 (92.3\%) of them had PSD, compared to $36.4 \%$ of patients with MRS scores between 0 and 3 who had PSD $(p<0.001)$. In the same vein, out of the 47 who scored 16 and above on the NIHSS, $40(85.1 \%)$ participants were depressed compared to $12.3 \%$ of those who scored $0-15$ who had PSD. This result was significant $(p<0.001)$.

Localisation of stroke characteristics, which was taken from CT and MRI reports of survivors, revealed a higher level of depression in the left hemisphere (52.1\%) compared to the right hemisphere (35.5\%); however, PSD and stroke localisation had no statistically significant association $(p=0.214)$. The rest of the results are summarised in Table 1 to Table 3

\section{Independent determinants of post-stroke depression}

The independent determinants of PSD analysed by binary logistic regression are shown in Table 4. Determinants include age ( $p=0.001$, adjusted odds ratio [OR] 0.030, 95\% confidence interval $[\mathrm{CI}]=0.01-0.220)$, stroke severity $(p<0.001, \mathrm{OR}=49.062, \mathrm{CI}=9.593-250.925)$, previous admission $(p<0.001, \mathrm{OR}=53.515, \mathrm{CI}=6.633-431.776)$, disability status $(p<0.001, \mathrm{OR}=4.234, \mathrm{CI}=2.456-7.231)$, as well as employment status, cognitive impairment and perceived social support.

\section{Discussion}

The main findings of the present study were prevalence of PSD of $42.9 \%$ and that the independent determinants of PSD were decreasing age, unemployment, perceived poor social support, increasing number of previous hospital admissions 
TABLE 1: Test of association between depression and socio-demographic characteristics using chi-square.

\begin{tabular}{|c|c|c|c|c|c|c|}
\hline \multirow[t]{2}{*}{ Variables } & \multirow{2}{*}{$\begin{array}{c}\text { Total } \\
(n=112)\end{array}$} & \multicolumn{2}{|c|}{$\begin{array}{c}\text { Depressed } \\
(n=48)\end{array}$} & \multicolumn{2}{|c|}{$\begin{array}{l}\text { Non-depressed } \\
\quad(n=64)\end{array}$} & \multirow[t]{2}{*}{$\begin{array}{c}\text { Test of } \\
\text { significance }\end{array}$} \\
\hline & & $n$ & $\%$ & $n$ & $\%$ & \\
\hline \multicolumn{7}{|l|}{ Gender } \\
\hline Females & 45 & 23 & 51.10 & 22 & 48.90 & $\chi^{2}=2.093$ \\
\hline \multirow[t]{2}{*}{ Males } & 67 & 25 & 37.30 & 42 & 62.70 & $d f=1$ \\
\hline & & & & & & $p=0.148$ \\
\hline \multicolumn{7}{|l|}{ Marital status } \\
\hline Presently not married & 32 & 14 & 43.80 & 18 & 56.20 & $\chi^{2}=0.150$ \\
\hline \multirow[t]{2}{*}{ Presently married } & 80 & 34 & 42.50 & 46 & 57.50 & $d f=1$ \\
\hline & & & & & & $p=0.904$ \\
\hline \multicolumn{7}{|l|}{ Ethnicity } \\
\hline Yoruba & 71 & 27 & 38.00 & 44 & 62.00 & $\chi^{2}=1.847$ \\
\hline \multirow[t]{2}{*}{ Other } & 41 & 21 & 51.20 & 20 & 48.80 & $d f=1$ \\
\hline & & & & & & $p=0.174$ \\
\hline \multicolumn{7}{|l|}{ Religion } \\
\hline Christianity & 78 & 33 & 42.30 & 45 & 57.70 & $\chi^{2}=0.032$ \\
\hline \multirow[t]{2}{*}{ Islam } & 34 & 15 & 44.10 & 19 & 55.90 & $d f=1$ \\
\hline & & & & & & $p=0.859$ \\
\hline \multicolumn{7}{|l|}{ Level of education } \\
\hline Primary or less & 16 & 9 & 56.20 & 7 & 43.80 & $\chi^{2}=1.416$ \\
\hline Secondary & 43 & 18 & 41.90 & 25 & 58.10 & $d f=2$ \\
\hline Tertiary and above & 53 & 21 & 39.60 & 32 & 60.40 & $p=0.493$ \\
\hline \multicolumn{7}{|l|}{ Employment status } \\
\hline Unemployed & 28 & 22 & 78.60 & 6 & 21.40 & $\chi^{2}=19.609$ \\
\hline Employed & 17 & 6 & 35.50 & 11 & 64.50 & $d f=2$ \\
\hline Self-employed & 67 & 20 & 29.00 & 47 & 71.00 & $p<0.001^{*}$ \\
\hline \multicolumn{7}{|c|}{ Perceived social support } \\
\hline Good & 12 & 2 & 16.70 & 10 & 83.30 & $\chi^{2}=13.749$ \\
\hline Fair & 90 & 37 & 41.10 & 53 & 58.90 & $d f=2$ \\
\hline Poor & 10 & 9 & 90.00 & 1 & 10.00 & $p=0.001^{*}$ \\
\hline
\end{tabular}

$\chi^{2}=$ chi-square; $d f$, degree of freedom

$p=$ level of significance $*<0.05$; bold numbers indicate statistical significance.

because of stroke, stroke severity, present disability status and cognitive impairment.

This prevalence is consistent with that witnessed in similar studies in Nigeria, which reported a range from $40 \%$ to $42 \%, 16,19,20$ however, it is much higher than the $22.9 \%{ }^{22}$ and $25.5 \%{ }^{12}$ found in Lagos and lower than the $52.9 \%$ reported by Mshelia et al., ${ }^{21}$ also conducted in Nigeria. It is to be noted that certain other studies conducted locally have found prevalences ranging from $16.2 \%$ to $30 \%{ }^{13,14,15,17,18}$

Overall, the $42.9 \%$ found in the present study is consistent with hospital-based studies of PSD in other parts of the world, which reported a rate ranging from $35 \%$ to $53 \%, 31,32$ whereas community-based studies reported lower rates, ranging from $9 \%$ to $23 \%{ }^{11,33}$

A close observation of the possible reasons for this variability may be connected with (1) the number of patients assessed and (2) methodological problems in recognising, assessing and diagnosing depression. Local studies with sample sizes of less than 100 patients for PSD reported a prevalence of $30 \%$ or less. It is possible that these studies either did not consider sample sizes that were representative of the base populations or used small samples that were not sufficient to give the studies the required power to address
TABLE 2: Test of association between depression and clinical or illness-related characteristics using chi-square.

\begin{tabular}{|c|c|c|c|c|c|c|}
\hline \multirow[t]{2}{*}{ Variables } & \multirow[t]{2}{*}{$\begin{array}{c}\text { Total } \\
(n=112)\end{array}$} & \multicolumn{2}{|c|}{$\begin{array}{l}\text { Depressed } \\
(n=48)\end{array}$} & \multicolumn{2}{|c|}{$\begin{array}{c}\text { Non- } \\
\text { depressed } \\
(n=64)\end{array}$} & \multirow[t]{2}{*}{$\begin{array}{c}\text { Test of } \\
\text { significance }\end{array}$} \\
\hline & & $n$ & $\%$ & $n$ & $\%$ & \\
\hline \multicolumn{7}{|l|}{ Previous admission } \\
\hline 1 & 95 & 33 & 34.7 & 62 & 65.3 & $\chi^{2}=17.525$ \\
\hline 2 & 10 & 8 & 80 & 2 & 20 & $d f=2$ \\
\hline 3 or more & 7 & 7 & 100 & 0 & 0 & $p<0.001 *$ \\
\hline \multicolumn{7}{|l|}{ Neuroimaging } \\
\hline Left hemisphere & 48 & 25 & 52.1 & 23 & 47.9 & $\chi^{2}=3.086$ \\
\hline Right hemisphere & 62 & 22 & 35.5 & 40 & 64.5 & $d f=2$ \\
\hline Both hemispheres & 2 & 1 & 50 & 1 & 50 & $p=0.214$ \\
\hline \multicolumn{7}{|l|}{ Aetiopathogenesis } \\
\hline Infarction & 88 & 38 & 43.2 & 50 & 56.8 & $\chi^{2}=0.018$ \\
\hline \multirow[t]{2}{*}{$\begin{array}{l}\text { Haemorrhage and } \\
\text { thrombotic }\end{array}$} & 24 & 10 & 41.7 & 14 & 58.3 & $d f=1$ \\
\hline & & & & & & $p=0.894$ \\
\hline \multicolumn{7}{|l|}{ MMSE } \\
\hline 24-30 (no impairment) & 104 & 40 & 38.5 & 64 & 61.5 & $\chi^{2}=9.112$ \\
\hline \multirow[t]{2}{*}{$\begin{array}{l}\text { 18-23 (mild } \\
\text { impairment) }\end{array}$} & 8 & 8 & 100 & 0 & 0 & $d f=1$ \\
\hline & & & & & & $p=0.003^{*}$ \\
\hline \multicolumn{7}{|l|}{ MRS } \\
\hline $\begin{array}{l}\text { 0-3 (good outcome } \\
\text { and not handicapped) }\end{array}$ & 99 & 36 & 36.4 & 63 & 63.6 & $\chi^{2}=59.028$ \\
\hline \multirow[t]{2}{*}{ 4-5 (handicapped) } & 13 & 12 & 92.3 & 1 & 7.7 & $d f=1$ \\
\hline & & & & & & $p<0.001 *$ \\
\hline \multicolumn{7}{|l|}{ NIHSS } \\
\hline $\begin{array}{l}0-15 \text { (forecast good } \\
\text { recovery) }\end{array}$ & 65 & 9 & 12.3 & 57 & 87.7 & $\chi^{2}=12.490$ \\
\hline \multirow[t]{2}{*}{$\begin{array}{l}16 \text { and above (forecast } \\
\text { severe stroke) }\end{array}$} & 47 & 40 & 85.1 & 7 & 14.9 & $d f=1$ \\
\hline & & & & & & $p<0.001 *$ \\
\hline
\end{tabular}

$\chi^{2}=$ chi-square; $d f$, degree of freedom; MMSE, Mini-Mental State Examination; MRS, Modified Rankin Scale; NIHSS, National Institute Health Stroke Scale.

$p=$ level of significance $*<0.05$; bold values indicate statistical significance.

the hypothesis, which may be responsible for the lower prevalence reported.

Moreover, most of the studies that used diagnostic tools reported higher prevalence compared to those that used screening instruments. This difference may be explained by the presence of physical symptoms like poor sleep and fatigue seen during the post-stroke period, which are also part of the diagnostic assessment of depression and may cause over-diagnosis; however, in this study, participants were assessed 6 months post-stroke to reduce this possibility.

For age, the result is in line with the study conducted by Mshelia et al. ${ }^{21}$ which found $73.8 \%$ of participants aged less than 35 years were depressed and the differences were statistically significant $(p=0.002)$. This is in tandem with various studies $^{34,35}$ that noted that PSD was more prevalent in the younger age group. Conversely, older age has been found to be significantly predictive of developing PSD in a number of studies. ${ }^{17,31}$ However, numerous studies have failed to yield a significant difference between age groups and PSD. ${ }^{15,36}$

This may be because survivors usually experience a reduced sense of control and a shift in life perspective, as stroke is recognised as taking away an anticipated future ${ }^{37}$; further, the onset of such an acute physical health problem requires 
TABLE 3: Test of association between depression and clinical and sociodemographic characteristics using the Mann-Whitney $U$ test.

\begin{tabular}{|c|c|c|c|c|c|}
\hline Variables & $\begin{array}{c}\text { Mean } \\
\text { rank }\end{array}$ & $\begin{array}{l}\text { Sum of } \\
\text { ranks }\end{array}$ & $\begin{array}{c}\text { Mann- } \\
\text { Whitney } U\end{array}$ & $\mathbf{z}$ & $p$ \\
\hline \multicolumn{6}{|l|}{ Age (years) } \\
\hline Depressed & 44.66 & 2143.50 & 967.50 & -3.352 & 0.001 \\
\hline Not depressed & 65.38 & 4184.50 & & & \\
\hline \multicolumn{6}{|c|}{ Monthly allowance (dollars) } \\
\hline Depressed & 46.41 & 2227.50 & 1051.50 & -12.872 & 0.004 \\
\hline Not depressed & 64.07 & 4199.50 & & & \\
\hline \multicolumn{6}{|c|}{ IIIness duration (months) } \\
\hline Depressed & 49.84 & 2392.50 & 1216.50 & -1.903 & 0.057 \\
\hline Not depressed & 61.49 & 3935.50 & & & \\
\hline \multicolumn{6}{|l|}{ MMSE } \\
\hline Depressed & 32.55 & 1562.50 & 386.50 & -6.869 & $<0.001$ \\
\hline Not depressed & 74.46 & 4765.50 & & & \\
\hline \multicolumn{6}{|l|}{ MRS } \\
\hline Depressed & 80.69 & 3873.00 & 375.00 & -7.204 & $<0.001$ \\
\hline Not depressed & 38.36 & 2455.00 & & & \\
\hline \multicolumn{6}{|l|}{ NIHSS } \\
\hline Depressed & 83.79 & 4022.00 & 226.00 & -8.329 & $<0.001$ \\
\hline Not depressed & 36.03 & 2306.00 & & & \\
\hline
\end{tabular}

MMSE, Mini-Mental State Examination; MRS, Modified Rankin Scale; NIHSS, National Institute Health Stroke Scale.

$p=$ level of significance $<0.05$; bold values indicate statistical significance.

TABLE 4: Binary logistic regression showing independent predictors of depression among 112 Nigerian stroke survivors.

\begin{tabular}{|c|c|c|c|}
\hline Variables & Adjusted odds ratio & $95 \%$ confidence interval & $p$ \\
\hline \multicolumn{4}{|c|}{ Age group (years) } \\
\hline$<50$ & 1 & & \\
\hline $50-60$ & 0.122 & $0.120-0.666$ & 0.015 \\
\hline$>60$ & 0.030 & $0.010-0.220$ & 0.001 \\
\hline \multicolumn{4}{|c|}{ Employment status } \\
\hline Unemployed & 1 & & \\
\hline Employed & 0.094 & $0.009-0.925$ & 0.043 \\
\hline Self-employed & 0.105 & $0.027-0.412$ & 0.001 \\
\hline \multicolumn{4}{|c|}{ Monthly allowance (dollars) } \\
\hline $0-130$ & 1 & & \\
\hline$>130$ & 1.043 & $0.027-0.412$ & 0.959 \\
\hline \multicolumn{4}{|l|}{ Social support } \\
\hline Good & 1 & & \\
\hline Fair & 7.633 & $0.957-59.614$ & 0.056 \\
\hline Poor & 92.431 & $3.712-2296.83$ & 0.006 \\
\hline \multicolumn{4}{|c|}{ Previous admission } \\
\hline 1 & 1 & & \\
\hline$\geq 2$ & 53.515 & $6.633-431.776$ & $<0.001$ \\
\hline \multicolumn{4}{|l|}{ NIHSS } \\
\hline $0-15$ & 1 & & \\
\hline$\geq 16$ & 49.062 & $9.593-250.925$ & $<0.001$ \\
\hline \multicolumn{4}{|l|}{ MRS } \\
\hline $0-3$ & 1 & & \\
\hline $4-5$ & 4.234 & $2.456-7.231$ & $<0.001$ \\
\hline \multicolumn{4}{|l|}{ MMSE } \\
\hline $24-30$ & 1 & & \\
\hline $18-23$ & 15.000 & $5.826-38.660$ & $<0.001$ \\
\hline
\end{tabular}

MMSE, Mini-Mental State Examination; MRS, Modified Rankin Scale; NIHSS, National Institute Health Stroke Scale.

$p=$ level of significance $<0.05$; bold values indicate statistical significance.

an individual to adapt rapidly in a highly emotional and changeable situation. Older people have a tendency to accept their difficulties because of past life experiences, resilience, declining optimism and physical ability, which provide a possible realistic adjustment and coping mechanisms and may be a protective factor.
Other emotional coping mechanisms such as having a health-focussed network of support and being familiar with healthcare systems are usually more readily available to older individuals compared to the younger ones, who feel despondent with a sudden and unexpected cessation of their dreams and aspirations following stroke and may feel unjustly deprived of a healthy life.

Regarding social support, the poorer it is, the higher the risk of PSD. This is consistent with other studies conducted locally ${ }^{38,39}$ and internationally. ${ }^{40}$ According to both the stress process model ${ }^{41}$ and the transactional model of stress and coping ${ }^{42}$ the outcome of a stressful event depends highly on the coping resources available. It is plausible in this case that social support serves as one of the effective coping mechanisms among stroke survivors. This may in turn influence their mental health. This explains why stroke survivors with good social support reported less depression.

It has been shown that the perception of availability of social support has the potency to make a person perceive a stressful situation as less stressful. ${ }^{43}$ This enhances the individual's capacity to cope with the situation. However, once depressive symptoms set in, the influence of social support becomes less significant; this may be because of a depressed stroke survivor having a reduced tendency to perceive the availability of social support, hence reducing the reality and perception of social support.

The result of PSD and cognitive impairment is consistent with that found in a similar study in Nigeria showing cognitive dysfunction as measured by MMSE to be significantly associated with PSD ${ }^{16}$; however, it is noteworthy that another study conducted in Nigeria found no statistically significant association between PSD and cognitive impairment. ${ }^{19}$

However, most studies have reported that stroke patients with major depression have a greater degree of cognitive impairment than non-depressed patients. ${ }^{35}$ This association could be explained by either cognitive impairment causing depression, as suggested by Anderson et al., ${ }^{44}$ or that depression leads to a greater degree of cognitive impairment, as corroborated by the fact that serotonin receptors binding in several brain regions correlated significantly with the MMSE scores of patients with PSD and cognitive impairment. ${ }^{45}$ Furthermore, patients who were effectively treated for PSD showed sustained improvement of cognitive functions over a 2-year period. ${ }^{46}$

Many studies have examined the issue of whether persons with severe stroke are more likely to develop PSD, and among them are studies conducted in Nigeria ${ }^{12,18}$ that found a statistically significant association between the severity of stroke and a greater risk of PSD.

Post-stroke depression is associated with functional ability and may have a negative impact on recovery. The result is consistent with findings from other similar studies, which reported that impaired functional status and disability 
measured by MRS or any other disability measure is significantly associated with PSD. ${ }^{12,21,47,48}$ This may be a result of the fact that after surviving a stroke, the majority of patients must cope with a multitude of disabilities in physical, psychological and social functioning. This burden of stroke can increase the risk of PSD, which then leads to further impairment like increased disability, reduced social activities, delayed recovery, failure to return to work and longer institutional care.

Conversely, depression in patients with chronic conditions like stroke is associated with poor outcomes, thereby sustaining severe levels of disability or worsening it. This is plausible through a number of bio-behavioural mechanisms like lack of treatment adherence, as well as lifestyle factors such as smoking and physical inactivity. Moreover, effective management of PSD improved not only patients' mood but their functionality as well. ${ }^{49}$

Post-stroke depression was not significantly associated with the hemispheric side of the lesion location for the study. The result of this study is in line with other local studies that looked at the association between lesion location and depression among stroke survivors..$^{21,22}$ No consensus can be found in the literature about this association, which remains controversial.

This study has some limitations, which include the crosssectional nature of the study, which has inherent limitations for interpretation of not allowing inferences of causality to be made. One tertiary study setting limits its generalisability in the community setting. Furthermore, the exclusion of patients with aphasia means that the results cannot be generalised to those stroke patients who have aphasia. It is equally important to note that social support was assessed in the study based on the perception of stroke survivors, notwithstanding the actual availability of support. This should be taken into consideration in interpreting findings of social support with PSD, although it is believed that social support is a subjective construct that centres primarily on the patient's perception and that its assessment should be based on perception. ${ }^{50}$

However, this is one of the few studies from Nigeria that made use of neuroimaging to make an exact definitive diagnosis, thus avoiding the possibility of misdiagnosis and inclusion of other neurological diagnoses with similar clinical presentation as stroke.

The study also used a diagnostic tool, the MINI, which can be used in primary care where the patients present, hence its applicability at routine clinics.

In conclusion, the PSD prevalence of $42.9 \%$ suggests that clinicians have to acknowledge that depression is a common outcome after stroke, especially when none of the stroke survivors who were studied had previous psychiatric assessment for depression. Furthermore, special attention should be given to stroke survivors with cognitive impairment who are younger ( $<50$ years), have poor social support, previous hospitalisation, low socio-economic status, more severe stroke and higher disability.

\section{Acknowledgements Competing interests}

The authors declare that they have no financial or personal relationship(s) that may have inappropriately influenced them in writing this article.

\section{Author(s) contributions}

O.O. was the project leader. O.O., A.A. and B.O. were responsible for idea generation and study conceptualisation. O.O. performed most of the data collection. O.C. and O.A. made conceptual contributions. O.O. and A.A. did the analysis and review of discussion.

\section{Funding}

This research received no specific grant from any funding agency in the public, commercial, or not-for-profit sectors.

\section{Data availability statement}

Data sharing is not applicable to this article as no new data were created or analysed in this study.

\section{Disclaimer}

The views and opinions expressed in this article are those of the authors and do not necessarily reflect the official policy or position of any affiliated agency of the authors.

\section{References}

1. Opara JA, Jaracz K. Quality of life of post stroke patients and their caregivers. J Med Life. 2010;3(3):216-219.

2. Kaste $\mathrm{ML}$, Folgelholm R, Rissanen $\mathrm{A}$. Economic burden of stroke and the evaluation of new therapies. Public Health. 1998;112:102-112. https://doi.org/10.1016/ S0033-3506(98)00593-9

3. Feign VL, Forouzanfan $\mathrm{MH}$, Krishnamurthi R, et al. Global and regional burden of stroke during 1990-2010. Lancet. 2014;383:245-255. https://doi.org/10.1016/ S0140-6736 (13)61953-4

4. GBD causes of Death Collaborators. Global, regional, and national age-sex specific mortality for 264 causes of death, 1980-2016: A systematic analysis for the Global Burden of Disease Study 2016. Lancet. 2017; 390:1151-1210. https://doi.org/ 10.1016/S0140-6736(17)32152-9

5. World Health Organisation: The Atlas of heart disease and stroke [homepage on the Internet]. 2010 [cited 2015 Mar 20]. Available from: http://www.who.int/ cardiovascular_diseases/en/cvdatlas/en

6. Feign VL, Lawes CM, Bennett DA, Baker-Collo SL, Parag V. Worldwide stroke incidence and early case fatality reported in 56 population based studies: $A$ systematic review. Lancet Neurol. 2009;8:355-369. https://doi.org/10.1016/S14744422 (09)70025-0

7. Adeloye D. An estimate of the incidence and prevalence of stroke in Africa: A systematic review and meta-analysis. PLoS One. 2014;9(6):e100724. https://doi. org/10.1371/journal.pone.0100724

8. Robinson RG. Neuropsychiatric consequences of stroke. Annal Rev Med 1997;48:217-229. https://doi.org/10.1146/annurev.med.48.1.217

9. Bhogal SK, Hackett ML, Craig SA. Lesion location and post stroke depression. A systematic review of the methodological limitations in the literature. Stroke J Am Heart Assoc. 2004;35:794-802.

10. Hackett ML, Anderson CS. Predictors of depression after stroke: Systematic review of observational studies. Stroke. 2005;36(10):2291-2301. https://doi.org/ 10.1161/01.STR.0000183622.75135.a4 
11. Berg A, Lonnqvist J, Palomaki H, Kaote M. Assessment of depression after stroke: A comparison of different screening instruments. Stroke. 2009:40:523-529. https://doi.org/10.1161/STROKEAHA.108.527705

12. Oladiji, JO, Akinbo SRA, Aina OF, Aiyejusunle CB. Risk factors of post stroke depression among stroke survivors in Lagos, Nigeria. Afr J Psychiatr. 2009;12:47-51. https://doi.org/10.4314/ajpsy.v12i1.30278

13. Abubakar SA, Isezuo SA. Health related quality of life stroke survivors: Experience of a stroke unit. Int J Biomed Sci. 2012;8(3):183-187.

14. Badaru UM, Ogwumike OO, Adeniyi AF, Olowe O. Variation in functional independence among stroke survivors having fatigue and depression. Neurol Res Int. 2013;2013:842980. https://doi.org/10.1155/2013/842980

15. Ojagbemi A, Owolabi M, Atalabi M, Baiyewu O. Stroke lesions and post stroke depression among survivors in Ibadan, Nigeria. Afr J Med Sci. 2013;42(3):245-251.

16. Ojagbemi A, Akinyemi R, Baiyewu O. Cognitive dysfunction and functional limitations are associated with major depression in stroke survivors attending rehabilitation in Nigeria. NeuroRehabilitation. 2014;34(3):455-456.

17. Abubakar SA, Obiekor RO, Subir AA, Iwuozwo EU, Magaji MI. Depression in long term stroke survivors. Sub-Saharan Afr J Med. 2014;1:119-123.

18. Imarhiagbe FA, Owolabi A. Post stroke depression in a sub-Saharan Africans. Validation of the Japanese stroke scale for depression. Sahel Med J. 2015;18 121-125. https://doi.org/10.4103/1118-8561.169285

19. Ibeneme SC, Anyachukwu CC, Nwosu A, Ibeneme GC, Bakare M, Fortwengel G. Symptoms of post-stroke depression among stroke survivors: An appraisal of psychiatry needs and care during psychotherapy rehabilitation. Scientifica. 2016;2016:5646052. https://doi.org/10.1155/2016/5646052

20. Fatoye FO, Mosaku SK, Komolafe MA, et al. Depressive symptoms and associated factors following cerebrovascular accident among Nigerians. J Ment Health. 2009;18:3. https://doi.org/10.1080/09638230701879094

21. Mshelia AA, Onyencho VC, Adebowale TO. Demographic and clinical factors on depression among stroke patients. Am J Clin Med Res. 2016;4(3):38-42.

22. Oni OD, Olagunju AT, Olisah VO, Aina OF, Ojini FI. Post-stroke depression: Prevalence, associated factors and impact on quality of life among outpatients in a Nigerian hospital. S Afr J Psychiat. 2018;24(0):a1058. https://doi.org/10.4102/ sajpsychiatry.v24i0.1058

23. Van de weg FB, Kuik DJ, Lankhorst GJ. Post stroke depression and functiona outcome: A cohort study investigating the influence of depression on functional recovery from stroke. Um Rehabil. 1991;13:268-272.

24. Robinson RG, Jorge RD. Post stroke depression: A review. Am J Psychiatr. 2016;173:221-231. https://doi.org/10.1176/appi.ajp.2015.15030363

25. Robinson RG, Spalletta G. Post stroke depression: A review. Can J Psychiatr. 2010;55(6):341-349. https://doi.org/10.1177/070674371005500602

26. Hackett ML, Pickles K. Part I: Frequency of depression after stroke: An updated systematic review and meta-analysis of observational studies. Int J Stroke. 2014;9:1017-1025. https://doi.org/10.1111/ijs.12357

27. Adewuya AO, Afolabi MO, Ola BA, et al. Relationship between depression and quality of life in persons with HIV infection in Nigeria. Int J Psych Med. 2008;38(1):43-51. https://doi.org/10.2190/PM.38.1.d

28. Onwuekwe IO. Assessment of mild cognitive impairment with mini mental state examination among adults in southeast Nigeria. Ann Med Health Sci Res. 2012;2(2):99-102. https://doi.org/10.4103/2141-9248.105653

29. Ekeh B, Ogunniyi A, Isamade E, Ekrikpo U. Stroke mortality and the predictors in a Nigerian teaching hospital. Afr Health Sci. 2015;15(1):74-81. https://doi.org/ 10.4314/ahs.v15i1.10

30. Maarten U, Roy E, Patrick C, et al. Optimizing cut-off scores for the Barthel index and modified Rankin scale for defining outcome in acute stroke trials. Stroke. 2005;36:1984-1987. https://doi.org/10.1161/01.STR.0000177872.87960.61
31. Caeiro L, Ferro JM, Santos CO, Figueira ML. Depression in acute stroke. J Psychiatry Neurosci. 2006;31(6):377-383.

32. House A, Dennis M, Mogridge L. Mood disorders in the year after first stroke. Br J Psychiatr. 1991;158(4):83-92. https://doi.org/10.1192/bjp.158.1.83

33. Appelros $P$, Vittanen $M$. Prevalence and predictors of depression at one year in a Swedish population-based cohort with first ever stroke. J Stroke Cerebrovasc Disc 2004;13:52-57. https://doi.org/10.1016/j.jstrokecerebrovasdis.2004.02.005

34. Robinson RG, Bolduc PL, Price TR. Two-year longitudinal study of post stroke mood disorders: Diagnosis and outcome at one and two years. Stroke. 1983;18(5):837-843. https://doi.org/10.1161/01.STR.18.5.837

35. Eriksson M, Asplund K, Glader EL, et al. Self-reported depression and use of antidepressant after stroke; a national survey. Stroke J Am Heart Assoc. 2004;35(4):936-941. https://doi.org/10.1161/01.STR.0000121643.86762.9a

36. Huang HT, Chuang YH, Lin PC, Lee BO, Chen $\mathrm{CH}$. Depression in older residents with stroke living in long term care facilities. JNR. 2014;22(2):111-118. https://doi. org/10.1097/jnr.0000000000000028

37. Liadlaw K. Post stroke depression and CBT with older people. In: D. GallagherThompson, AM Steffen, LW Thompson, editors. Handbook of behavioral and cognitive therapies with older adults. New York: Springer, 2008; p. 233-248.

38. Vincent-Onabajo GO, Muhammad MM, Ali MU, Masta MA, Aliyu HN. Social support after stroke. Influence of source of support on stroke survivors. Health related quality of life. Int Neuropsychiatr Dis J. 2016;5(1):1-9. http://doi.org/ 10.9734/INDJ/2016/20240

39. Gbiri CA, Akinpelu AO, Odole AC. Prevalence, pattern and impact of depression on quality of life of stroke survivors. Int J Psychiatr Clin Pract. 2010;14(3):198-203. https://doi.org/10.3109/13651501003797633

40. Morris PLP, Robinson RG, Raphael B. The relationship between the perception of social support and post stroke depression in hospitalized patients. Psychiatry. 1991;54:306-315. https://doi.org/10.1080/00332747.1991.11024559

41. Pearlin LI, Mullan JT, Semple SJ, Skaff MM. Caregiving and the stress process. An overview of concepts and their measures. Gerontologist. 1990;30:583-594. https://doi.org/10.1093/geront/30.5.583

42. Palmer S, Dryden W. Counseling for stress problems. London: Sage; 1995.

43. Lakey B, Cohen S. Social support theory and measures measuring and intervening in social support. New York: Oxford University Press; 2000.

44. Anderson G, Vesteergaard K, Rus JO. Intellectual impairment in the first year following stroke, compared to an age matched population sample. Cerebrovasc Dis. 1996;6(6):363-369. https://doi.org/10.1159/000108054

45. Morris PLP, Robinson RG, Samuels J. Depression, introversion and mortality following stroke. Aust N Z J Psychiatry. 1993;27(3):443-449. https://doi. org/10.3109/00048679309075801

46. Narushima K, Robinson RG. The effect of early versus late antidepressant treatment on physical impairment associated with post stroke depression: Is there a time related therapeutic window? J Nerv Ment Dis. 2003;191(10):645-652. https://doi org/10.1097/01.nmd.0000092197.97693.d2

47. Brown C, Hasson $H$, Thyselius V, Almborg AH. Post stroke depression and functional independence: A conundrum. Acta Neurologica Scandinavica. 2012;126:45-59. https://doi.org/10.1111/j.1600-0404.2011.01595.x

48. De Ryck A, Brouns R, Geurden M, Elseviers M, De deyn PP, Engelborghs S. Risk factors for post stroke depression: Identification of inconsistencies based on a systematic review. J Geriatr Psychiatry Neurol. 2014;27(3):147-158. https://doi. systematic review. J Geriatr Psych
org/10.1177/0891988714527514

49. Chemerinski E, Robinson RG, Kosier JT. Improved recovery in activities of daily living associated with remission of post stroke depression. Stroke. 2001:32:113-117. https://doi.org/10.1161/01.STR.32.1.113

50. Cobb S. Presidential Address-1976. Social support as a moderator of life stress. Psychosom Med. 1976;38(3):300-314. https://doi.org/10.1097/00006842 197609000-00003 